\title{
Internacionalização e Ativismo Judicial: Causas Políticas e Causas Jurídicas nas Décadas de 1990 e 2000*
}

Fabiano Engelmann**

\section{Introdução}

Os fenômenos de internacionalização do direito vinculados à importação/exportação de causas políticas traduzidas para o espaço judiciário por juristas vinculados a um padrão de militantismo político e jurídico são relacionados neste artigo. A abordagem desse processo é realizada a partir de uma pesquisa que envolve fundamentalmente duas dimensões. A primeira compreende a análise de decisões judiciais e a produção de "doutrina jurídica" sobre as causas coletivas e a definição dos "direitos humanos". Estes dados permitem um primeiro retrato do perfil das causas que são legitimadas no âmbito de uma instituição representativa de um espaço jurisdicional internacional, a Corte Interamericana de Direitos Humanos.

\footnotetext{
*Artigo recebido em janeiro de 2006 e aceito para publicação em maio de 2006.

**Professor do Departamento de Ciências Sociais da Universidade Federal de São Carlos (UFSCarlos).
} 
A segunda dimensão consiste na análise de dois casos representativos de Organizações Não Governamentais (ONGs) promotoras de causas coletivas vinculadas às definições de "direitos humanos" na década de 1990, por intermédio de entrevistas com dirigentes dessas entidades. Os casos analisados fornecem indicações que permitem a apreensão de um padrão de estratégias e recursos utilizados para a legitimação de causas políticas no espaço judicial na década de 1990.

A exportação/importação de causas coletivas tem por mecanismo a formação de redes de advogados que podem se apresentar como "redes formais", associadas ao movimento internacional dos "direitos humanos", ou "redes informais", vinculadas às diversas formas de militantismo e defesa judicial de determinados grupos. Nesses termos, a apreensão dessas redes implica a análise das relações dessa modalidade de ativismo judicial com o militantismo político e com os investimentos realizados na construção da causa coletiva relacionada a diversas espécies de direitos. Pode-se mencionar, entre essas modalidades, o pertencimento a determinado partido político, $\mathrm{ONG}$, movimento social ou órgão de defesa corporativa, como sindicatos patronais ou de empregados.

A problemática da mobilização de repertórios de "crítica" da tradição jurídica e de "novos" usos do direito, representada pelos advogados engajados em causas coletivas, é um fenômeno historicamente presente de forma mais explícita no âmbito do "direito do trabalho"1 e da advocacia para sindicatos de trabalhadores, e também na década de 1970, na defesa de presos políticos, articulada por advogados vinculados às redes internacionais de promoção de "direitos humanos". Na década de 1990, no Brasil, tais modalidades de engajamento se modificam principalmente na relação com movimentos sociais em que grupos de advogados investem na tradução ${ }^{2}$ e construção, no universo do direito, das "causas políticas" constituídas no espaço dos movimentos sociais. 


\section{Internacionalização e Ativismo Judicial:}

Causas Políticas e Causas Jurídicas...

Tal fenômeno comporta uma série de especificidades que estão estreitamente relacionadas à ascensão de grupos de juristas vinculados aos investimentos na redefinição "social" do direito e no militantismo político. No âmbito das carreiras de Estado, o processo de legitimação relaciona-se a uma nova definição para o "papel político" destas, em que se destacam a Magistratura e o Ministério Público. Da mesma forma, o fenômeno está relacionado à redefinição institucional do país, a partir da Constituição de 1988, e às condições de possibilidade de uso do direito, geradas a partir da relativa autonomização do Poder Judiciário.

Um conjunto de pesquisas realizadas nos Estados Unidos e na França tem relacionado o fenômeno da internacionalização e a emergência de modalidades de uso do espaço judicial para a promoção de causas coletivas, particularmente o conjunto de trabalhos identificados à noção de cause lawyer (advogado de causas) desenvolvida por Austin Sarat e Stuart Scheingold ${ }^{3}$ ao longo da década de $1990^{4}$. Da mesma forma, há uma importante vertente analítica desenvolvida em um conjunto de trabalhos que propõem uma sociologia do campo jurídico na França, contribuindo para melhor definição dessa problemática. Notadamente, as pesquisas desenvolvidas na década de 1990 e 2000 por Dezalay (1993, 2001), Dezalay e Garth (2002), Israel (2001a) e Roussel (2002, 2003).

Os trabalhos realizados nessa perspectiva analisam as alterações que ocorrem nos mundos jurídicos norte-americano e francês, tanto no espaço de produção das decisões judiciais, quanto no das profissões jurídicas relacionadas à emergência desse padrão de advocacia engajada. De acordo com tais pesquisas, a especificidade de engajamento político pelo direito envolve a análise das estratégias dos movimentos sociais na apropriação do espaço judicial, o papel dos juristas na tradução e formalização das "causas políticas" na linguagem das disputas no interior do Judiciário, e a conciliação da atuação profissional com o militantismo político. 
Outros fatores considerados por essas pesquisas são a emergência de um espaço internacional de construção de causas por intermédio de sua exportação e importação e a constituição de redes internacionais entre advogados. A internacionalização é forte nas causas relacionadas aos "direitos humanos", principalmente pela ação de ONGs. Conforme indicam Dezalay e Garth (2002), o recurso aos fóruns internacionais de denúncia de torturas, prisões arbitrárias e os repertórios de doutrina jurídica produzidos a partir das concepções de "direitos humanos" foram utilizados, principalmente, para criar uma alternativa ao fechamento do Estado ao longo das ditaduras na América Latina. ${ }^{5}$ Em um segundo momento, o militantismo político vinculado ao ativismo dos "direitos humanos" passa a um investimento maior na utilização de instrumentos institucionais, o que, em alguma medida, como apontado adiante, pode ser relacionado à redemocratização política do país.

No caso latino-americano, e mais especificamente nos casos do Brasil e da Argentina, Meili (1998, 2001) distingue dois padrões de configuração de engajamento de advogados em causas coletivas: um baseado em redes formais (formalized-issue networks) e, em grande medida, internacionalizadas, e outro baseado em redes informais de cooperação entre advogados (informally organized networks). No caso brasileiro, Meili (2001) refere que há uma diminuição das redes formais, constituídas a partir das comissões de "direitos humanos" da Ordem dos Advogados do Brasil (OAB) durante o regime militar, para grupos de advogados que passam a atuar na advocacia dos movimentos sociais. Como representativo, pode-se mencionar o caso da Rede Nacional de Advogados e Advogadas Populares agrupando escritórios de advocacia que prestam assessoria a movimentos sociais de "luta pela moradia" e "sem-terra", 6 entre outros.

Em um outro sentido, as redes mais formais e internacionalizadas que permanecem estão ligadas aos movimentos e temáticas tais como a "proteção do meio ambiente", "direito das mulheres", "direi- 
tos dos índios", "luta contra a violência", que são articulados a partir de ONGs especializadas. Essa inflexão, de movimentos organizados calcados predominantemente na denúncia e na busca da preservação de direitos e garantias individuais, pode ser percebida no perfil das entidades que se especializaram no ativismo judicial na década de 1990.

\section{Causas Coletivas e "Direitos Humanos" no Espaço Judicial Nacional e Internacional}

Para se obter um primeiro panorama geral dos temas que são classificados no espaço judicial brasileiro como concernentes aos "direitos humanos" e causas coletivas, analisou-se o conjunto de demandas propostas na Corte Interamericana de Direitos Humanos de 1970-2005, um conjunto de demandas que podem ser identificadas a causas coletivas nos tribunais brasileiros entre 1988 e 2005, além de um conjunto de artigos e livros de "doutrina jurídica" publicados no Brasil entre 1997 e $2005 .^{7}$ As palavras-chave utilizadas para uma primeira pesquisa de ementas nas bases de dados dos tribunais foram: "internacionalização do direito", "globalização e direito", "direitos humanos", "direitos coletivos" e "Corte Interamericana de Direitos Humanos". Resultaram como consequiência e foram utilizadas para refinamento da pesquisa as expressões: "direito indígena", "direito internacional público", "direito ambiental", "direito globalizado", "Pacto de San José da Costa Rica", "Convenção de Haia", "Movimento dos Trabalhadores Rurais Sem Terra (MST)".

O Quadro 1 mostra a predominância de causas que são definidas como de "direitos humanos", seguida das causas coletivas mais recorrentes, vinculadas aos direitos dos "sem-terra" e aos "direitos ambientais". A aplicação estrita do Pacto de San José, que representa a lei específica da Corte Interamericana de Direitos Humanos, aparece 


\section{Fabiano Engelmann}

\section{Quadro 1}

Ementas e Acórdãos Pesquisados: Tribunais X Temas (1988-2005)

\begin{tabular}{|c|c|c|c|c|c|}
\hline TRIBUNAIS PESQUISADOS & $\begin{array}{c}\text { TEMA } \\
\text { Direitos } \\
\text { Humanos }\end{array}$ & $\begin{array}{c}\text { TEMA } \\
\text { Direitos } \\
\text { Ambientais }\end{array}$ & $\begin{array}{c}\text { TEMA } \\
\text { Pacto de } \\
\text { San José }\end{array}$ & $\begin{array}{c}\text { TEMA } \\
\text { MST }\end{array}$ & $\begin{array}{c}\text { TEMA } \\
\text { Direitos } \\
\text { Indígenas }\end{array}$ \\
\hline Supremo Tribunal Federal & 1 & 7 & 1 & 2 & 5 \\
\hline Superior Tribunal de Justiça & 3 & 2 & 0 & 4 & 5 \\
\hline Tribunal Regional Federal 1ㄹ Região & 13 & 4 & 0 & 4 & 9 \\
\hline Tribunal Regional Federal 2ª - Região & 6 & 0 & 0 & 0 & 0 \\
\hline Tribunal Regional Federal 3 ${ }^{\text {a }}$ Região & 6 & 0 & 0 & 0 & 0 \\
\hline Tribunal Regional Federal 4- Região & 16 & 9 & 0 & 1 & 6 \\
\hline Tribunal de Justiça/Rio Grande do Sul & 10 & 0 & 0 & 0 & 0 \\
\hline TOTAL & 55 & 22 & 1 & 11 & 25 \\
\hline
\end{tabular}

Fonte: INTERNACIONALIZAÇÃO E USOS DO DIRETO NO RIO GRANDE DO SUL (2005). ${ }^{8}$

em apenas um caso, indicando a pequena legitimação do Instituto da Corte Interamericana de Direitos Humanos no espaço judicial nacional. Em termos de distribuição de regiões do país, a maior incidência das causas coletivas analisadas está na chamada terceira região, que compreende o Norte e o Centro-oeste. Das causas que chegam ao Supremo Tribunal Federal, onde está em pauta a discussão das regras constitucionais, destacam-se as relativas aos direitos ambientais. A existência de apenas uma ocorrência abrigada sob a definição de "direitos humanos" pode indicar que há a substituição dessa definição por expressões como os "direitos fundamentais" exaustivamente previstos na Constituição.

Entretanto, importa observar que há uma disparidade entre as causas que chegam aos dois tribunais nacionais, e os tribunais regionais que possuem maior volume de causas coletivas, o que também se projeta para a Corte Interamericana de Direitos Humanos na qual o Brasil fica atrás de outros países na América Latina. A utilização da Corte Interamericana pressupõe o esgotamento dos recursos judiciais nos tribunais internos. 


\section{Internacionalização e Ativismo Judicial:}

Causas Políticas e Causas Jurídicas...

Nos quadros seguintes encontramos um comparativo do uso pelos países latino-americanos da Corte Interamericana de Direitos Humanos e os respectivos temas recorrentes no período analisado. Estes temas foram classificados a partir da noção jurídica de "fato típico" tal como consta na classificação oficial utilizada pela Corte.

\section{Quadro 2}

Demandas Pautadas na Corte Interamericana de Direitos Humanos entre 1970 e 1985

\begin{tabular}{|c|c|c|c|c|c|c|c|c|c|}
\hline Fato Típico & Brasil & $\begin{array}{l}\text { Argenti- } \\
\text { na }\end{array}$ & $\begin{array}{c}\text { Chi- } \\
\text { le }\end{array}$ & $\begin{array}{l}\text { Colôm- } \\
\text { bia }\end{array}$ & - Hai- & Uruguai & $\begin{array}{l}\text { Equa- } \\
\text { dor }\end{array}$ & $\begin{array}{l}\text { Guate- } \\
\text { mala }\end{array}$ & Total \\
\hline $\begin{array}{l}\text { Dever de Adotar } \\
\text { Dispositivo de Direito } \\
\text { Interno }\end{array}$ & $x$ & $\mathrm{X}$ & $x$ & & $\mathrm{X}$ & $x$ & $x$ & & \\
\hline $\begin{array}{l}\text { Direito de } \\
\text { Reconhecimento da } \\
\text { Personalidade } \\
\text { Jurídica }\end{array}$ & $x$ & $x$ & $x$ & & $x$ & $x$ & $x$ & & \\
\hline Direito à Vida & $x$ & $x$ & $x$ & 1 & $x$ & $x$ & $x$ & 1 & 2 \\
\hline $\begin{array}{l}\text { Direito à Integridade } \\
\text { Física }\end{array}$ & $x$ & $x$ & $x$ & & $x$ & $x$ & $x$ & 1 & 1 \\
\hline Liberdade Pessoal & $x$ & $x$ & $x$ & & $x$ & $x$ & $x$ & & \\
\hline Integridade Pessoal & $x$ & $x$ & $x$ & 1 & $x$ & $x$ & $\mathrm{X}$ & 1 & 2 \\
\hline Garantias Judiciais & $x$ & $\mathrm{x}$ & $\mathrm{X}$ & 1 & $x$ & $x$ & $x$ & & 1 \\
\hline $\begin{array}{l}\text { Liberdade, } \\
\text { Consciência e } \\
\text { Religião }\end{array}$ & $x$ & $\mathrm{X}$ & $x$ & & $x$ & $x$ & $x$ & & \\
\hline $\begin{array}{l}\text { Liberdade de } \\
\text { Pensamento e } \\
\text { Expressão }\end{array}$ & $x$ & $x$ & $x$ & & $x$ & $x$ & $x$ & & \\
\hline $\begin{array}{l}\text { Direito de Circulação } \\
\text { e Residência }\end{array}$ & $x$ & $x$ & $\mathrm{X}$ & & $x$ & $x$ & $x$ & & \\
\hline Proteção Judicial & $x$ & $x$ & $x$ & & $x$ & $x$ & $x$ & 1 & 1 \\
\hline Total de Casos & $\mathbf{X}$ & $\mathbf{X}$ & $\mathbf{X}$ & 3 & $\mathbf{x}$ & $\mathbf{x}$ & $\mathbf{x}$ & 4 & \\
\hline
\end{tabular}

Fonte: INTERNACIONALIZAÇÃO E USOS DO DIRETO NO RIO GRANDE DO SUL (2005). 


\section{Fabiano Engelmann}

No período que corresponde predominantemente aos regimes militares nos países latino-americanos (1970-1985), observa-se uma pequena proposição de demandas na Corte Interamericana de Direitos Humanos, à exceção da Colômbia e da Guatemala, que apresentam, mesmo assim, pequena frequiência.

\section{Quadro 3}

Demandas Pautadas na Corte Interamericana de Direitos Humanos entre 1986 e 2005

\begin{tabular}{|c|c|c|c|c|c|c|c|c|c|}
\hline Fato Típico & Brasil & $\begin{array}{l}\text { Argen- } \\
\text { tina }\end{array}$ & $\begin{array}{c}\text { Chi- } \\
\text { le }\end{array}$ & $\begin{array}{l}\text { Colôm- } \\
\text { bia }\end{array}$ & Haiti & $\begin{array}{l}\text { Uru- } E \\
\text { guai }\end{array}$ & $\begin{array}{l}\text { Equa- } \\
\text { dor }\end{array}$ & $\begin{array}{l}\text { Guate- } \\
\text { mala }\end{array}$ & - Total \\
\hline $\begin{array}{l}\text { Dever de Adotar Dispositivo } \\
\text { de Direito Interno }\end{array}$ & 1 & 1 & 1 & & & $x$ & 1 & & 4 \\
\hline $\begin{array}{l}\text { Direito de Reconhecimento } \\
\text { da Personalidade Jurídica }\end{array}$ & & & & & & $x$ & 1 & & 1 \\
\hline Direito à Vida & & 1 & & 2 & 1 & $\mathrm{x}$ & 1 & 1 & 6 \\
\hline Direito à Integridade Física & 1 & 1 & & 1 & 1 & $x$ & 3 & 1 & 8 \\
\hline Liberdade Pessoal & & 1 & & & & $\mathrm{X}$ & & & 1 \\
\hline Integridade Pessoal & 1 & & & 1 & & $x$ & 4 & 2 & 8 \\
\hline Garantias Judiciais & 1 & 2 & & 1 & & $x$ & 4 & 3 & 11 \\
\hline $\begin{array}{l}\text { Liberdade de Consciência e } \\
\text { Religião }\end{array}$ & & & 1 & & & $x$ & & & 1 \\
\hline $\begin{array}{l}\text { Liberdade de Pensamento e } \\
\text { Expressão }\end{array}$ & & & 1 & & & $\mathrm{x}$ & & 2 & 3 \\
\hline $\begin{array}{l}\text { Direito de Circulação e } \\
\text { Residência }\end{array}$ & & & & & & $x$ & & 1 & 1 \\
\hline Proteção Judicial & 1 & 2 & & 2 & & $x$ & 4 & 2 & 11 \\
\hline Total de Casos & 5 & 8 & 3 & 7 & 2 & $\mathbf{x}$ & 18 & 12 & \\
\hline
\end{tabular}

Fonte: INTERNACIONALIZAÇÃO E USOS DO DIRETO NO RIO GRANDE DO SUL (2005).

No período que corresponde à democratização da maioria destes países (1986-2005), há um incremento na utilização da Corte. Tal fator pode ser tributado ao fato de que nos países democráticos o uso do recurso a instituições jurisdicionas internacionais ocorre como recurso judicial final após o esgotamento das instâncias nacionais.

O perfil das causas que chegam à Corte se refere predominantemente a direitos e garantias individuais, destacando-se "proteção judicial", "garantias judiciais", "direito à integridade física" e "pessoal". Os 
países com maior freqüência de demandas são Equador e Guatemala, destacando-se ainda, respectivamente, Colômbia e Argentina.

O Quadro 3 indica que, ao menos no que tange ao uso de instituições internacionais, ainda predominam como causas de "direitos humanos" as vinculadas às demandas de direitos e garantias individuais, em detrimento das mobilizações de tradução para o espaço judicial de "causas coletivas". Estas últimas também reivindicam o uso de instituições nacionais e internacionais para fazer valer direitos sociais, como analisado a seguir nas modalidades de ativismo judicial representativas das décadas de 1990 e 2000.

\section{Modalidades de Militantismo Político por Intermédio do Direito}

Na construção das causas coletivas envolvendo militantes políticos e uso do direito, há um amalgamento entre o discurso militante e a expertise, como analisam Michel e Willemez (2002) para o caso dos sindicatos franceses entre 1970 e 1990. Esse fenômeno se reproduz também no ambiente dos "movimentos sociais" em que entram em jogo especialidades relacionadas à mobilização do "conhecimento científico", como no caso dos "ambientalistas". Tais análises contribuem para demonstrar que a reconversão de segmentos de advogados no universo do engajamento militante em uma causa corresponde à crescente utilização por parte dos "movimentos sociais" desse recurso, ocorrendo também um efeito de "especialização" dos militantes.

No caso brasileiro, os advogados relacionados à militância política por intermédio do direito constituem uma modalidade de agentes que conseguiram ascender no espaço jurídico combinando a expertise jurídica com um conjunto de relações estabelecidas pelo militantismo. Nesse pólo, a passagem como "liderança" em organizações de 
esquerda com atuação no movimento estudantil e a forte formação e inserção em movimentos religiosos (teologia da libertação, juventude universitária católica etc.) aparecem como recursos e porta de entrada no mundo da política.

O ingresso nessa advocacia envolve a atuação em serviços de assistência judiciária, prestados pelas universidades ou órgãos públicos, e a atuação no movimento estudantil. As possibilidades de estagiar em entidades públicas, identificadas a uma "causa política" e o contato com a fundamentação "alternativa" do direito, propiciado pelo universo do militantismo, constituem uma porta de entrada importante para profissionalização como "advogado de movimentos sociais" ou de setores socialmente dominados. Nessa categoria, compreende-se desde os advogados relacionados à defesa das causas dos "direitos humanos", com maior atuação na oposição ao regime militar, até, na década de 1990, os advogados do "movimento dos sem-terra" e os relacionados à advocacia ligada à questão "indígena" e "ambiental".

Nesses casos, as disposições para "ajudar os pobres" e as afinidades com uma formação familiar religiosa forte contribuem para a adesão às "causas políticas" de segmentos sociais dominados. Em especial, destacam-se os movimentos em que estão explicitamente em jogo as regras atinentes ao "direito de propriedade", como no caso da regularização fundiária dos "sem-teto" ou da defesa judicial do "Movimento dos Sem Terra". Também se pode contabilizar nesse espaço os advogados ligados a sindicatos e partidos políticos de esquerda abrindo caminho para a ascensão a postos públicos na base dos cargos em comissão na esfera estatal, que têm como requisito a titulação em direito.

As possibilidades de reconversão são garantidas pelos padrões estruturais de organização da advocacia, que permite que os advogados circulem entre as esferas de Estado e da iniciativa privada. O pertencimento a um escritório de advocacia especializado na defesa de 
"trabalhadores" colabora para a acumulação de capitais reconversíveis na disputa pela ocupação de postos públicos, o que ocorre sem prejuízo da posição alcançada na advocacia. O efeito contrário também é válido. O capital político acumulado no âmbito das burocracias, principalmente relacionadas a secretarias de estado, comissões parlamentares encarregadas da "questão social", como comissões e secretarias de "direitos humanos", ação social e reforma agrária permite a participação, ao mesmo tempo, como sócio em uma banca de advocacia especializada.

Outra dimensão importante a analisar no contexto dessa advocacia engajada se refere ao seu grau de internacionalização, que pode ser medido na existência de redes formais relacionadas à causa coletiva defendida pela ligação com o espaço das ONGs. A seguir, são expostos dois casos que podem ser tomados como representativos do processo descrito. O primeiro consiste na especialização na defesa jurídica feminista, ligada ao "movimento internacional dos 'direitos humanos"”. O segundo caso é o da ONG Acesso à Terra: Cidadania e Direitos Humanos, vinculada à Rede Nacional de Advogados e Advogadas Populares (Renap), que promove direitos dos movimentos de "Luta pela Moradia" e do movimento dos "sem-terra", ambas as ONGs têm sede no estado do Rio Grande do Sul.

\section{- Direito das Mulheres enquanto Causa Jurídica: 0 Caso da ONG Themis}

O movimento de "direitos humanos" no Brasil e na América Latina está intrinsecamente relacionado aos movimentos políticos de contestação das ditaduras militares da década de 1970. Ele está articulado a uma nova "fundamentação de esquerda" que se forma no âmbito norte-americano, com a exportação de um modelo de "respeito aos direitos civis e políticos" (DEZALAY; GARTH, 2002, p. 212). ${ }^{9}$ No caso do Rio Grande do Sul, a defesa dos "direitos civis e políticos", 
seguindo a tendência já apontada na primeira parte deste trabalho, está relacionada, em um primeiro momento, a um movimento mais "político" do que "jurídico"; da mesma forma, a ligação com mecanismos internacionais é frágil.

A criação da comissão de "direitos humanos" da seccional sul-rio-grandense da OAB foi articulada com esse movimento, denominando-se "Comissão Sobral Pinto de Direitos Humanos". Na Assembléia Legislativa do Rio Grande do Sul, foi criada a primeira Comissão de "Direitos Humanos" parlamentar do Brasil. Tal comissão contribuiu para a institucionalização do movimento no estado, tendo servido como espaço para denúncias, principalmente, de casos de violência policial.

Como uma segunda modalidade do movimento dos "direitos humanos", mais arraigado ao espaço jurídico, pode-se apontar a maior profissionalização e especialização das ONGs, principalmente na defesa de direitos coletivos. O fenômeno do surgimento de ONGs internacionalizadas e especializadas em defesas de causas coletivas está inserido no processo de diversificação do espaço jurídico e das respectivas apropriações e usos do direito advindos na década de 1990 no Brasil. Tanto no caso das ONGs especializadas, quanto dos advogados de "movimentos sociais", há forte intercâmbio com o mundo da política partidária.

As redes de advocacia ligadas a ONGs não prescindem de participar das disputas acerca do sentido do direito. Portanto, há uma forte aliança com o espaço da produção das fundamentações relacionadas aos diversos saberes disciplinares, no sentido de instrumentalizar o uso do aparelho judiciário pelos advogados engajados, a partir de redefinições das noções de "justiça", "ética" e "direito". Postura que aproxima tais movimentos do mundo acadêmico especializado na definição "teórica" das diversas disciplinas jurídicas, particularmen- 
te do segmento mais radicalizado representado pelo "direito alternativo". 10

É nesse espaço de uso do direito e engajamento de advogados em causas coletivas que se insere o caso representativo da ONG Themis. A entidade tem como peculiaridade a assessoria jurídica e a tradução da "causa política" relacionada ao movimento feminista para o espaço judicial. Insere-se em um contexto mais amplo de "explosão de ONGs feministas", que ocorre na América Latina na década de 1990. Conforme Alvarez (1998) (militante feminista), pode-se opor ONGs mais "aptas tecnicamente, transnacionalizadas e profissionalizadas" (p. 51), que detêm um saber especializado sobre as "questões relacionadas a mulheres e que presta consultoria a órgãos estatais" (p. 52), a outro tipo de organização que se volta para a "mobilização política e à luta por direitos" (p. 52).

Nesse sentido, estabelece-se no quadro das definições nativas do trabalho da ONG uma contradição entre sua natureza de produtora de problemas políticos e jurídicos, relacionada aos demais "movimentos sociais", e sua perspectiva "paraestatal". A última tendência intensifica-se na medida em que a organização abriga em seus quadros agentes especializados, detentores de uma expertise que pode ser reconvertida também na ocupação de espaços no interior da burocracia, de comissões legislativas ou, mesmo, na prestação de consultoria a órgãos de Estado.

No caso em pauta, a autodefinição da entidade e a trajetória de suas fundadoras tendem a posicioná-la no espaço dos "movimentos sociais". Entretanto, o processo de reconhecimento e legitimação estatal de direitos e políticas públicas, reivindicadas pela entidade, projeta suas integrantes como potenciais ocupantes de postos no interior do estado. A origem da ONG está no "movimento feminista" do Rio Grande do Sul, tendo sido fundada, em 1993, por três advogadas. As referências para a fundação da entidade vêm por intermédio da parti- 


\section{Fabiano Engelmann}

cipação das fundadoras em um congresso do Comitê Latino-americano e do Caribe para a Defesa dos Direitos da Mulher (Cladem) em 1992. Desde o início das atividades da ONG, já há estreita ligação com os movimentos internacionais de "direitos humanos".

As advogadas fundadoras da Themis militam no "movimento de mulheres" do Rio Grande do Sul e, posteriormente, passam a apresentarem-se como integrantes do movimento de "direitos humanos", conforme relata uma de suas fundadoras:

"As três fundadoras eram do movimento de mulheres e não eram do movimento de 'direitos humanos'. Eu era do movimento de 'direitos humanos'e não tinha uma trajetória no movimento feminista. Em 1990, fui à Columbia University fazer um curso de 'direitos humanos' que me deu todo um olhar para a importância de trabalhar na perspectiva internacional para poder garantir a eficácia dos 'direitos humanos' localmente e eu vim com esta bagagem de lá, e isto era um momento em que se colocava esta questão dos 'direitos humanos' das mulheres em 1993. E isto foi uma constelação mesmo de interesse. Claro que as fundadoras do projeto da ONG tinham uma compreensão desta conjuntura internacional e elas estavam procurando outros paradigmas para a luta feminista, não os paradigmas tradicionais da igualdade da mulher, muitas vezes tendo o homem como um elemento negativo. Não era essa a perspectiva. A Themis trabalha com dois paradigmas, "direitos humanos' e gênero. Os dois representam uma mudança bem grande" (Entrevista concedida ao autor deste artigo por Virgínia Feix, coordenadora da ONG em 3/12/2002).

O percurso comum das "fundadoras" é a passagem pelo movimento estudantil sem adesão partidária. Os vínculos político-partidários são estabelecidos a partir da participação no "movimento de mulheres" e resultam na filiação a um partido político de esquerda. A passagem pela Comissão de "Direitos Humanos" na Assembléia Legislativa e a militância política denotam a imbricação do engajamento na defesa judicial feminista com o mundo político e as condições de possibilidade de mediação dessa militância com o campo jurídico, por meio da especialização e adesão à causa dos "direitos humanos". 
A fusão entre o conhecimento jurídico e a militância política explicita-se também em iniciativas da entidade. Além do trabalho de defesa judicial de "mulheres vítimas da violência doméstica", a ONG investe na "mobilização política", por meio de um programa de formação de "promotoras legais populares", que consiste em educar "lideranças comunitárias" e traduzir um conjunto de noções da linguagem técnica jurídica, específicas das "relações" entre "gênero" e "direito".

O encaminhamento de demandas judiciais ocorre por um programa de "advocacia feminista" que visa assessorar juridicamente mulheres que tenham direitos violados. Uma terceira frente de atuação são os programas relacionados a estudos e publicações sobre "gênero e direito", por meio da criação de um centro de documentação e da participação de seus quadros em diversos cursos de formação, em que se discutem concepções jurídicas "alternativas".

A construção dessa expertise jurídica a favor da causa do "direito das mulheres" compreende, ao mesmo tempo, duas frentes de atuação. Por um lado, a mobilização de repertórios do "direito internacional" para acessar instituições como a Corte Interamericana de Direitos Humanos apelando para tratados internacionais como recurso a decisões judiciais desfavoráveis às petições da entidade no espaço judicial nacional. Por outro lado, um investimento na "crítica" da tradição jurídica, pela mobilização de repertórios de (re)fundamentação do direito.

Da mesma forma, o apelo ao direito internacional e aos institutos relacionados ao Sistema Interamericano de Direitos demonstra a mobilização dos recursos adquiridos em cursos e contatos no exterior. Os centros irradiadores dessas tecnologias jurídicas e instrumentos de uso do direito são norte-americanos. Entretanto, não se traduzem em cursos de alta especialização acadêmica e longa duração, mas de 
curta duração e com formação instrumental visando o treinamento de ativistas especializados.

A relação com os "movimentos críticos do direito" e com outras associações de juristas mantém a característica de reivindicar "um espaço na agenda para as questões de gênero e raça", além da construção de um "campo conceitual" que articule "gênero e direito". A articulação com outras associações de profissionais do direito, principalmente juízes e promotores públicos, envolve o reforço de redes que se estabelecem informalmente entre "amigos" e "simpatizantes da causa". Contatos que compreendem professores de direito, advogados e juízes ligados a "movimento do direito alternativo".

O envolvimento da entidade com associações de juristas é indicativo da passagem da articulação baseada em redes informais de "simpatizantes da causa" para uma articulação formalizada com as associações de classe, sobretudo das carreiras de Estado (Magistratura e Ministério Público). Dessa forma, demonstra também o papel que essas associações assumem no sentido de se posicionarem politicamente em nome dos segmentos que representam e sua articulação com outros movimentos políticos e jurídicos.

A seguir, é apresentado outro caso representativo da modalidade de advocacia que promove causas coletivas vinculadas mais especificamente aos direitos sociais.

\section{A Defesa dos Pobres como Causa Jurídica: 0 Caso da Rede Nacional de Advogados e Advogadas Populares (Renap)}

Um segundo caso representativo de modalidade de advocacia engajada politicamente compreende um grupo de advogados ligado aos 


\section{Internacionalização e Ativismo Judicial:}

Causas Políticas e Causas Jurídicas...

movimentos do catolicismo social e ao militantismo no Partido dos Trabalhadores (PT). Esse grupo tem nas organizações da Igreja Católica, particularmente nas Comunidades Eclesiais de Base (CEBs), uma de suas fontes de articulação.

Pode-se tomar como representativa da advocacia nessa modalidade a Renap. Trata-se de uma rede que vincula informalmente um conjunto de escritórios de advocacia, cuja ligação ocorre pela prática da “advocacia para movimentos sociais" ou, como se autodefinem, para o "povo". No caso do Rio Grande do Sul, essa rede está vinculada ao trabalho realizado pela ONG Acesso-Cidadania e Direitos Humanos, liderada pelo advogado Jacques Alfonsin, procurador do Estado, aposentado e integrante da fundação do Movimento de Justiça e Direitos Humanos no Rio Grande do Sul, no final da década de 1970. Conforme Alfonsin (2002), a característica dessa advocacia é a promoção de causas coletivas:

"Os que buscam a assistência jurídica da Renap raríssimamente estão sozinhos. Eles pertencem, de regra, a uma coletividade qualquer, que ultrapassa o indivíduo, a família, o grupo, a categoria profissional, a qual se encontra na mesma situação dele(a)s. Sua principal característica é a da pobreza, da carência ou em alguns casos, da miséria. Há um perfil classista na situação que os impele a buscar socorro jurídico, muitas vezes infenso a ser organizada, inclusive, como pessoa jurídica. Organizações informais e formais, movimentos populares, como o MST (Movimento de Sem-Terra), MMTR (Movimento das Mulheres Trabalhadoras Rurais), MPA (Movimento dos Pequenos Agricultores), MAB (Movimento dos Atingidos por Barragens), MNLM (Movimento Nacional de Luta pela Moradia), CPT (Comissão Pastoral), CEBS (Comunidades Eclesiais de Base), MTD (Movimento dos Trabalhadores Desempregados), Movimentos e Comissões de 'direitos humanos', Sindicatos Rurais e Pastorais, grupos de pessoas dedicadas à defesa de 'direitos humanos' violados pela tortura, pelo racismo, pelas prisões ilegais, ou à defesa de crianças e adolescentes, de homossexuais, do direito à livre expressão através de rádios comunitárias, entre outras, têm procurado apoio nos serviços jurídicos da Renap" (ALFONSIN, 2002, p. 22). 
Esse conjunto, que mescla militantismo e utilização do direito, investe, ao mesmo tempo, na produção de definições jurídicas, pela publicação de artigos em edições específicas que objetivam "formar advogados", inserindo-se em um pólo específico de ativismo judicial. A relação com a Igreja se estabelece pelo apoio financeiro e pela estrutura material, como locais para reunião, mas, principalmente, serve como porta de entrada de advogados militantes. Além disso, outro aspecto a ser destacado é a fundamentação por meio do "catolicismo social" das "teses" apresentadas por esse perfil de uso do direito, quando entram em jogo as noções de "justiça social" e defesa do "pobre" em relação aos "ricos".

A trajetória de Jacques Alfonsin é representativa dessa vinculação a um "grupo de juristas cristãos" de projeção nacional, que se reúne a partir do movimento de "direitos humanos" na década de 1970 e, posteriormente, na década de 1990, organiza a Rede Nacional de Advogados Populares. Os articuladores dessa rede em São Paulo são juristas com projeção nacional que unem o militantismo político, a participação nos movimentos de "direitos humanos" e um forte investimento no debate intelectual com a publicação de artigos e livros de "doutrina jurídica". Os principais expoentes desse grupo são Plínio de Arruda Sampaio, advogado, deputado federal pelo PT e candidato a governador de São Paulo em 1990; Hélio Bicudo, promotor público, ex-deputado federal pelo PT, vice-prefeito de São Paulo (2000-2004); e Dalmo de Abreu Dallari, professor da Faculdade de Direito da Universidade de São Paulo (USP), secretário dos Negócios Jurídicos na Prefeitura na gestão de Luíza Erundina (à época no PT), entre 1990 e 1992.

Participa também do grupo o jurista Fábio Konder Comparatto, professor da Faculdade de Direito de São Paulo. Pela ligação com a Igreja, Sampaio, Bicudo, Dallari e Comparatto atuaram nos "movimentos de direitos humanos" promovendo a defesa de presos políticos e a denúncia de tortura ao longo do regime militar. A origem comum do 
grupo é a passagem pela direção da Comissão de Justiça e Paz da Arquidiocese de São Paulo, que inicia suas atividades em 1972 e se destaca por atividades de denúncias e representação judicial de presos políticos. ${ }^{11}$

A produção das “causas jurídicas" dos "pobres" relaciona-se às disposições presentes na formação religiosa, combinadas com a fundamentação moral de "ajudar os pobres". Da mesma forma, a busca de instrumentos teóricos que possam enfrentar conceitos jurídicos sobre a propriedade denunciados como parte de uma "dogmática conservadora" envolve a tradução do catolicismo social em forma de doutrina jurídica. A advocacia politicamente engajada permite, ao mesmo tempo, "independência" em relação às estruturas partidárias e uma adesão maior aos "movimentos sociais", assim como a "advocacia trabalhista”, nas décadas de 1970 e 1980, permitia uma ligação à causa coletiva dos "trabalhadores" por meio do sindicalismo. Para esses segmentos, a possibilidade de "agir por intermédio do direito" em favor dos grupos socialmente dominados mobilizando as diversas fundamentações morais e "doutrinárias" tem um custo menor do que a atuação orgânica no "mundo da política", sendo também esse fenômeno indicativo da relativa autonomização do campo jurídico no Brasil ao longo da década de 1990.

\section{Considerações Finais}

Pode-se detectar uma tendência a um novo padrão de engajamento em causas coletivas no Brasil indicado pelo caso representativo de uso do espaço judicial das duas ONGs analisadas. Nestes casos, observa-se que o recurso ao espaço judicial se relaciona à busca de efetivação de direitos legitimados como princípios na Constituição de 1988. Em tal sentido, diferentemente do ativismo político que envolveu segmentos de juristas que buscaram alternativas fora do Estado para denunciar o descumprimento dos direitos e garantias individuais, na década de 1990, essas iniciativas se dirigem para a construção de 


\section{Fabiano Engelmann}

fundamentações e para a busca de decisões judiciais que possam ter repercussão na esfera estatal.

Esse movimento ainda não se reflete de forma significativa em instâncias internacionais, como a Corte Interamericana de Direitos Humanos, na qual predominam as causas vinculadas aos direitos e garantias individuais, mesmo que essa Corte tenha ampliado significativamente sua influência entre os países na América Latina ao longo da redemocratização política. A assimilação de causas coletivas internacionais que circulam por meio de redes de ONGs, fóruns e mesmo pelo ensino jurídico implica uma forma específica de relação com a circulação internacional de idéias e princípios jurídicos que já possui repercussão nos tribunais nacionais e que poderá também repercutir em novos usos das instâncias jurisdicionais internacionais que se encontram em processo de consolidação.

\section{Notas}

1. A respeito da construção das "teses coletivas" no âmbito do direito do trabalho, ver Biavaschi (1998).

2. Sobre a utilização do direito na tradução de "causas políticas" para o espaço judicial por movimentos sociais, ver Spanou (1989).

3. Sobre a noção de cause lawyer e suas possibilidades de uso, ver Sarat e Scheingold (1998, 2001). Nesta perspectiva, para o caso francês, mais recentemente há o trabalho de Gaiti e Israel (2003), Israel (2001a, 2001b) e Spanou (1989).

4. Especificamente sobre o engajamento da American Bar Association no apoio aos advogados de presos condenados à morte e na construção da causa da abolição da pena de morte, ver Sarat e Scheingold (2001).

5. Este fenômeno de construção de um espaço de juristas identificados com a "causa dos 'direitos humanos"” e articulados com a Igreja Católica é particular- 


\section{Internacionalização e Ativismo Judicial: \\ Causas Políticas e Causas Jurídicas...}

mente nítido no caso chileno, conforme demonstram Dezalay e Garth (2002) e também o trabalho de Garland (2003).

6. Para um maior detalhamento da concepção dessa rede, ver Alfonsin (2002).

7. Entre as obras que fornecem um mapa de definições dos "direitos humanos" e causas coletivas, destacam-se Araújo (2000), Cançado Trindade (1999), Comparatto (2001), Piovesan (2000) e Hanashiro (2001).

8. Banco de dados do projeto "Internacionalização e usos do direito no Rio Grande do Sul". Tal banco foi constituído a partir de um projeto de pesquisa com o mesmo nome financiado pela Fundação de Amparo à Pesquisa do Estado do Rio Grande do Sul (FAPERGS) e desenvolvido no Centro Universitário Feevale, instituição localizada no município de Novo Hamburgo, ao longo do ano de 2005. O projeto de pesquisa foi coordenado pelo autor, sendo a análise dos dados publicada neste artigo.

9. Sobre a gestão dos programas internacionais de promoção dos "direitos humanos", ver Guilhot (2003).

10. Para um maior detalhamento a respeito da relação do "movimento do direito alternativo" com o ensino universitário, ver Engelmann (2006).

11. Para um maior detalhamento sobre a atuação política e jurídica da Comissão de Justiça e Paz de São Paulo, ver Cancian (2005).

\section{Referências Bibliográficas}

ALFONSIN, J. T. Dos nós de uma lei e de um mercado que prendem e excluem aos nós de uma justiça que liberta. In: DORA, D. D. Direito e mudança social. Rio de Janeiro: Renovar, Fundação Ford, 2002.

ALVAREZ, S. E. A explosão de ONGs feministas latino-americanas. In: Programas de capacitação legal. Porto Alegre: ONG Themis, 1998.

ARAÚJO, L. I. de A. Da globalização: do direito internacional público - os choques regionais. Rio de Janeiro: Editora Lúmen Júris, 2000.

BIAVASCHI, M. B. Magistratura e transformação social: as teses coletivas dos juízes gaúchos. 1998. Dissertação (Mestrado em Direito) - Universidade Federal de Santa Catarina, Florianópolis, 1998. 
CANÇADO TRINDADE, A. A. Tratado de Direito Internacional dos direitos humanos. Porto Alegre: Sergio Fabris Editor, 1999.

CANCIAN, R. Comissão de justiça e paz de São Paulo: gênese e atuação política (1972-1985). São Carlos: Ed. UFSCAR, 2005.

COMPARATTO, Fábio Konder. A afirmação histórica dos direitos humanos. 2. ed. São Paulo: Ed. Saraiva, 2001.

DEZALAY, Y. La production doctrinale comme objet et terrain de luttes politiques et professionnelles. In: POIRMEUR, Y. et al. La doctrine juridique. Paris: CURAPP-PUF, 1993.

. Constructing law out of power: investing in human rights as an alternative political strategy. In: SARAT, A.; SCHINGOLD, S. (Ed.). Cause lawyering in the State in a global era. Oxford, New York: Oxford University Press, 2001. (Coleção Oxford Socio-Legal Studies).

; GARTH, B. The internationalization of Palace of Wars: lawyers, economists, and the contest to transform Latin American State. Chicago: The Chicago Series in Law and Society, Apr. 2002.

ENGELMANN, F. Sociologia do campo jurídico: juristas e usos do direito. Porto Alegre: Sergio Antonio Fabris Editor, 2006.

GAITI, B.; ISRAEL, L. Sur l' engajement du droit dans la construction des causes. Politix, v. 16, n. 62, 2003.

GARLAND, D. G. Formulation et réformulation d'une cause, le cas des droits de l'homme au Chili, de la dictature à la politique de reconciliation nationale. Politix, v. 6, n. 62, 2003.

GUILHOT, N. Os profissionais da democracia em ação. In: LINS, D.; WACQUANT, L. (Org.). Repensar os Estados Unidos: por uma sociologia do superpoder. Campinas: Papirus, 2003.

HANASHIRO, O. S. M. P. O sistema interamericano de proteção aos "direitos humanos". São Paulo: EdUSP, 2001.

INTERNACIONALIZAÇÃO E USOS DO DIREITO NO RIO GRANDE DO SUL. Novo Hamburgo, RS: Centro Universitário Feevale, 2005.

ISRAEL, L. Cadres et motifs de l' action résistante: l' exemple du Front National des Juristes (1941-1944). In: CEFAI, C.; TROM, D. Les formes de l'action collective: mobilisation dans des arènes publiques. Paris: École des Hautes Études en Sciences Sociales, 2001a. 


\section{Internacionalização e Ativismo Judicial: \\ Causas Políticas e Causas Jurídicas...}

Usages militants du droit dans 1' arène judiciaire: la "cause lawyering". Droit et Societé, n. 49, 2001 b.

MEILI, S. Cause lawyers and social movements: a comparative perspective on democratic change in Argentina and Brazil. In: SARAT, A.; SCHINGOLD, S. (Ed.). Cause lawyering political commitments and professional responsabilities. New York: Oxford University Press, 1998. (Coleção Oxford Socio-Legal Studies).

Latin American cause-lawyering networks. In: SARAT, A.; SCHINGOLD, S. (Ed.). Cause lawyering in the State in a global era. New York: Oxford University Press, 2001. (Coleção Oxford Socio-Legal Studies).

MICHEL, H.; WILLEMEZ, L. Investissements savants et investissementes militants du droit du travail: syndicalists et avocats travaillistes dans la défense salaries. In: HAMMAN, P.; MÉON, J. M; VERRIER, B. Discours savants, discours militants: mélange des genres. Paris: L' Harmattan, 2002.

PIOVESAN, F. Direitos humanos, democracia e integração regional: os desafios da globalização. Revista da Faculdade de Direito de São Bernardo do Campo, v. 6, t. 2, 2000.

ROUSSEL, V. Affaires de juges: les magistrats dans les scandales politiques en France. Paris: La Découverte, 2002.

Les magistrats français, des cause lawyers malgré eux. Politix - La Cause du Droit, v. 16, n. 62, 2003.

SARAT, A.; SCHEINGOLD, Stuart. Cause lawyering and the reproduction of professional authority: an introduction. In: (Ed.). Cause lawyering political commitments and professional responsabilities. New York: Oxford University Press, 1998. (Coleção Oxford Socio-Legal Studies).

State transformation, globalization, and the possibilities of cause lawyering: an introduction. In: (Ed.). Cause lawyering in the State in a global era. New York: Oxford University Press, 2001. (Coleção Oxford Socio-Legal Studies).

SPANOU, C. Le droit instrument de la contestation sociale? Les noveaux movements sociaux face au droit. In: LOCHAK, D. (Org.). Les usages sociaux du droit. Paris: PUF, 1989. 
Resumo

\section{Internacionalização e Ativismo Judicial: Causas Políticas e Causas Jurídicas nas Décadas de 1990 e 2000}

Pretende-se fornecer elementos para a análise da relação entre o fenômeno de internacionalização do direito e a emergência de advogados engajados na representação judicial de causas coletivas. São analisadas duas dimensões: uma primeira expõe um panorama exploratório das causas coletivas no cenário nacional e internacional. Uma segunda dimensão de análise aborda casos representativos de promoção de causas nas décadas de 1990 e 2000. Estas duas dimensões permitem avançar a hipótese de que a redemocratização política e a constituição de redes internacionais de circulação de causas políticas e jurídicas contribuem para a definição dos perfis de ativismo judicial.

Palavras-chave: Internacionalização do Direito - Causas Coletivas Ativismo Judicial

\section{Abstract}

\section{International and Judicial Activism: Political and Juridical Causes in 1990 and 2000's}

The article intends to supply with elements the analysis of the relation between the phenomenon of internationalization of Law and the emergency of lawyers engaged in the judicial representation of collective causes. Two dimensions are analyzed: a first one displays a exploratory panorama of the causes in the national and international scene. One second dimension of analysis approaches representative cases of promotion of causes in the decades of 1990 and 2000. These two dimensions allow to advance the hypothesis of that the political redemocratization and the constitution of international nets of circulation of political and legal causes contribute for the definition of the profiles of judicial activism.

Keywords: Internationalization of Law - Collective Causes - Judicial Activism 